\title{
Female Urethral Reconstruction
}

\author{
Anne L. Ackerman • Jerry Blaivas • Jennifer T. Anger
}

Published online: 19 October 2010

(C) The Author(s) 2010. This article is published with open access at Springerlink.com

\begin{abstract}
Female urethral strictures are rare; thus, the literature describing stricture management in women is sparse. Although urethral dilation continues to be performed at a high frequency in women despite lack of proven efficacy, this procedure is used for a variety of voiding complaints other than stricture. Hence, the longterm utility of dilation and urethrotomy for urethral stricture in women is unknown. This review describes the various urethroplasty techniques used in the management of female urethral stricture. Although grafts using a dorsal approach have been shown to be feasible in women, ventral flap techniques offer good long-term outcomes with minimal morbidity. Acute and delayed management of pelvic fracture-associated urethral distraction defects in women is also described. Unlike in men, immediate urethroplasty in women should be performed once the patient is hemodynamically stable.
\end{abstract}

Keywords Urethroplasty · Techniques · Female - Vaginal flap $\cdot$ Buccal graft $\cdot$ Pelvic fracture

\section{Introduction}

Bladder outlet obstruction, of which true urethral stricture is only a minor component, is a rare entity in women. Retrospective analyses have estimated that only $3-8 \%$ of women who present to urologists with voiding complaints have a diagnosis of outlet obstruction [1]. Within this small

A. L. Ackerman · J. Blaivas · J. T. Anger $(\bowtie)$

UCLA Department of Urology,

1260 15th Street, Suite 1200,

Santa Monica, CA 90404, USA

e-mail: janger@mednet.ucla.edu population, the actual incidence of urethral stricture, the only subset of obstruction requiring urethral reconstruction, ranges from $4 \%$ to $13 \%$ among women with outlet obstruction, depending on the criteria used for diagnosis [2-4]. Given these numbers, the incidence of true urethral stricture in women presenting with voiding complaints would be $0.1-1 \%$ at greatest estimation. Very few women presenting to urologists with voiding complaints will ever require urethral reconstruction.

Female urethral stricture is typically iatrogenic, resulting from prior urethral dilations, difficult/traumatic catheterization with subsequent fibrosis, urethral surgeries (diverticulum surgery, fistula repair, anti-incontinence procedures), trauma (pelvic fracture), pelvic radiation, or acute/chronic urethritis/cystitis leading to fibrosis. There have been rare reports of urethral stricture resulting from urethral tuberculosis [5], vulvar dystrophy [6], lichen sclerosis [7], primary urethral carcinoma [8], urethral fibroepithelial polyps [9], urethral leiomyoma [10], bladder drainage of pancreatic transplants [11], post-transurethral resection of a bladder tumor [12], sacrococcygeal teratoma [13], or transsexual reconstruction [14].

\section{Work-up of Urethral Stricture in Women}

A diagnosis of urethral stricture is difficult to make based on symptomatology alone, as voiding symptoms correlate poorly with the presence of urethral obstruction in women $[15,16]$. Women typically complain of frequency and urgency, which are highly nonspecific. A voiding diary may help clarify the nature of the patient's voiding complaints and reveal less common symptoms of dysuria, hesitancy, dribbling, incontinence, recurrent urinary tract infections, or pain with micturition. Rarely does urethral stricture present 
with urinary retention, renal failure, hydronephrosis, or pyelonephritis [17, 18]. Although a history positive for prior pelvic trauma, pelvic surgery, or urethral dilations may suggest stricture, the diagnosis typically requires a combination of endoscopic and radiologic studies.

Initial evaluation should include a genitourinary and bimanual pelvic examination, with attention paid to the position and support of the urethrovesical junction. Any cystocele, vaginal scars, or masses should be noted, as should the general estrogenized or atrophic state of the vaginal epithelium. The presence of lichen sclerosis, which may cause meatal strictures in men and women, should be identified.

The combination of urodynamics with imaging, in the form of videourodynamics or in conjunction with a voiding cystourethrogram, can provide additional information about stricture location and length. Failure of the bladder neck and proximal urethra to open upon initiation of detrusor contraction suggests proximal bladder outlet obstruction, not urethral stricture. The classic "spinning top" appearance of the urethra on voiding with an open, dilated proximal urethra and narrowed area at the meatus is not diagnostic and is frequently seen in women with unobstructed voiding on urodynamics. As stricture is typically located at the distal third of the urethra or the meatus, imaging may reveal ballooning of the bladder neck on voiding. Although these images can be helpful, many women find it difficult to void in a standing position, and clean images are difficult to obtain in the seated position. When a voiding cystourethrogram is nondiagnostic, cystoscopy generally is confirmatory. Cystoscopy combined with urethral calibration using bougie à boule can help determine the caliber of the strictured urethra. Some strictures are apparent at cystoscopy as circumferential scars, similar to urethral strictures in men. In others, the patient cannot relax, and sphincteric contraction can make it difficult to visualize the stricture directly.

\section{Treatment Strategies: Role of Urethral Dilation and Urethrotomy}

Once a diagnosis of urethral stricture is made, surgical intervention is the appropriate treatment. The previous standard was a trial of conservative management with repeated office dilations. No conclusive clinical evidence suggests that this procedure has any benefit in this disease. If performed aggressively, dilation can result in bleeding, urinary extravasation, and stress urinary incontinence. Despite the rarity of true female urethral stricture, urethral dilation continues to be performed with high frequency. This is likely due to persistence of the practice of dilating the unstrictured female urethra for a wide variety of complaints despite a proven lack of efficacy [19]. The endurance of this practice may be related to the absence of consensus guidelines for the treatment of female urethral stricture, the historical use of this technique as a first-line treatment for a variety of lower urinary tract symptoms in women, and the financial reimbursements for this simple office-based procedure.

The evidence for urethral dilation and urethrotomy for true stricture disease is made up primarily of case reports and small series of patients with minimal follow-up [20, 21]. Internal urethrotomy or dilation was used by Massey and Abrams [22] to treat a variety of symptoms of obstructed voiding, resulting in symptomatic improvement in $80 \%$ of patients. Because this study included women with a variety of complaints and did not assess urodynamic parameters, the responses of the patient subset with true urethral stricture are unclear. In 1992, Takao et al. [23] examined 17 patients with urethral strictures diagnosed by urodynamics who were treated with gradual dilation to $30 \mathrm{~F}$ with metal sounds over increasing time intervals for 6 months. Mean urethral diameter increased from 18.1 to $23.5 \mathrm{~F}$, while average flow rates increased from 9.4 to $11.2 \mathrm{~mL} / \mathrm{s}$. Although the clinical end point involved urodynamic assessment, this study was seriously limited by a final assessment only 1 week after final dilation, with no additional follow-up. In a more recent study, Smith et al. [24] reported seven patients managed by initial urethral dilation to $30 \mathrm{~F}$ who were maintained on clean intermittent catheterization (CIC) with an 18- to 20-F catheter daily for 6 months. Patients reported a mean improvement in the American Urological Association (AUA) symptom score of 10.7 points; urodynamic parameters were not assessed. Three of the seven patients, however, required repeat dilations. A prospective, randomized trial of 49 patients compared urethral dilation with sounds with simple CIC for the management of recurrent urethral strictures [25]. Patients maintained on CIC alone had better objective urinary flow rates and better subjective quality-of-life scores. This study also noted an increased frequency of urinary tract infections in patients treated with dilation compared with those performing CIC.

Given the subjective responses noted in these studies, an initial trial of conservative treatment may be reasonable in selected patients with mild complaints. For most patients, however, definitive surgical treatment will be needed. The specific approach to urethroplasty should be tailored to each patient, with consideration of the location of the stricture, length of the stricture, and integrity of the bladder neck.

\section{Female Urethroplasty Techniques}

A good understanding of the regional anatomy is essential to performing a lasting surgical repair with minimal impact 
on continence and neurosensory function [26•]. The urethral wall contains two thick muscular layers, an inner longitudinal and an outer circular layer. This muscle thins as the urethra travels distally, which may explain the higher prevalence of distal meatal strictures in women. The muscular layers terminate into a thick collagenous ring in the distal fourth of the urethra that is minimally compliant; an overabundance of this collagenous tissue may be the anatomic basis for Lyon's ring, previously described in young girls with voiding dysfunction or recurrent urinary tract infections. The erectile tissue of the clitoris supports the urethra dorsally. The neurovascular bundles of the clitoris run along the ischiopubic ramus, below the pubic ramus in the midline. They coalesce to travel along the cephalad surface of the clitoral body toward the glans, away from dorsal dissection planes. Ventrally, the perineal membrane is a three-dimensional condensation associated with the compressor urethrae and the distal urethrovaginal sphincter, continuous with the arcus tendineus fascia of the pelvis (Fig. 1). The dorsal aspect of this structure is a transverse bilateral sheet that forms an inverted "U" of muscle attaching the lateral wall of the vagina and perineal body to the ischiopubic ramus. The perineal membrane and sphincter complex are at risk of damage with proximal

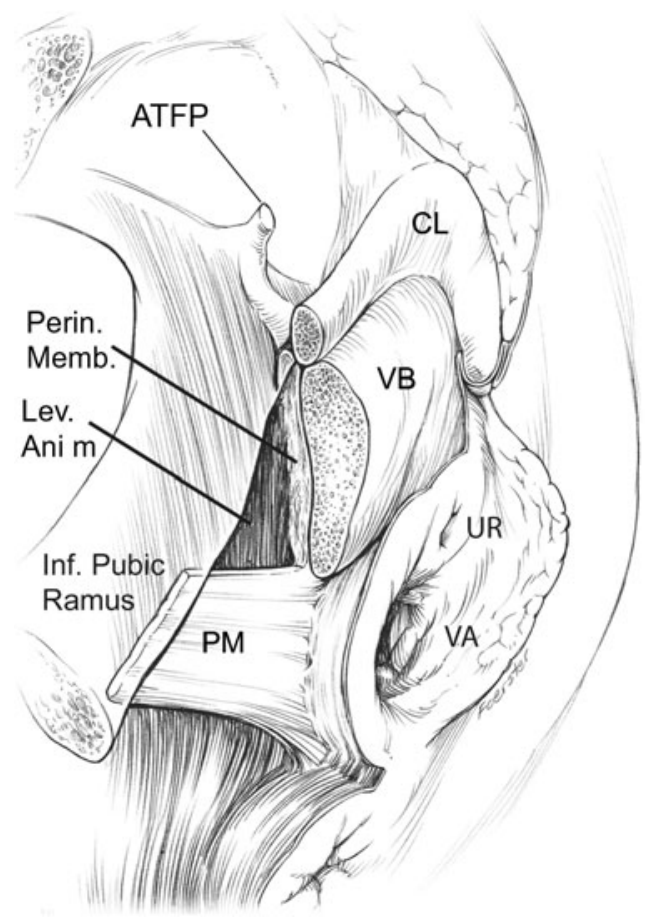

Fig. 1 Drawing of dissection revealing the perineal membrane (perin. memb. $[\mathrm{PM}]$ ) and showing its lateral attachment to the inferior pubic ramus (inf. pubic ramus). A window in the PM has been cut to reveal the attachment of the levator ani muscle (lev. ani $\mathrm{m}$ ) and its fusion with the vestibular bulb (VB). Extension to the arcus tendineus fascia pelvis (ATFP) is also shown inside the pubic bone attaching to its inner surface. $C L$ clitoris; $U R$ urethra; VA vagina. (From Stein and DeLancey [26•]; with permission) dissection in any plane. However, it is possible to dissect between the urethra and these structures and preserve continence. A solid understanding of urethral anatomy is necessary to expose the diseased urethral segment completely while avoiding damage to surrounding structures.

The principles of female urethral reconstruction differ from those in men. In women, excision and reanastomosis of an entire urethral segment is substantially more morbid and may risk stress incontinence. A ventral approach may be more comfortable for most surgeons, as development of a plane ventral to the urethra is more frequently performed in other vaginal procedures, and minimal to no urethral mobilization is required. A dorsal approach leaves the anterior vaginal wall untouched, minimizing any potential complications that might occur with later sling placement. This approach may preserve the normal anatomic positioning of the urethra upward, whereas ventral approaches tend to redirect the urethral meatus posteriorly; the significance of this in voiding is unclear. Some surgeons have been reluctant to perform dorsal repairs because of concerns for bleeding, damage to clitoral structures, stress incontinence, and neurosensory complications. Therefore, ventral onlay approaches are generally preferred, although the literature is insufficient to support one approach over another. The surgical techniques described here simply demonstrate feasibility (Table 1).

\section{Meatotomy}

For short meatal strictures unlikely to involve the voluntary sphincter, a simple ventral meatotomy can be effective in alleviating symptoms. The ventral aspect of the stricture and vaginal wall are incised into the healthy urethra; the edges are sewn transversely in a Heineke-Mikulicz fashion, leaving the urethra hypospadiac. In one study examining girls with meatal stenosis, 48 of 50 patients experienced resolution of recurrent urinary tract infections and improved voiding symptoms 1 year after meatotomy [27]. Although women must be warned of the possibility of spraying with voiding, this is generally less of an issue than it is with men. Women with superficial meatal stenosis are good candidates for a meatotomy.

\section{Ventral Incision and Reanastomosis}

For short midurethral strictures not involving the meatus, a longitudinal ventral incision through the stricture can open up the urethral lumen significantly. After incising the stricture longitudinally, the incision can be sutured transversely using the Heineke-Mikulicz principle. For short strictures, this technique can generate a wide-caliber urethra 
Table 1 Summary of urethroplasty techniques described for female strictures in the literature (excluding urethral distraction defects)

\begin{tabular}{|c|c|c|c|c|}
\hline Technique & Study & Study size, $n$ & Benefits & Risks \\
\hline \multirow[t]{3}{*}{ Urethral dilation } & Takeo et al. [23] (1992) & 17 & \multirow{3}{*}{$\begin{array}{l}\text { Minimally invasive, } \\
\text { office based }\end{array}$} & \multirow{3}{*}{$\begin{array}{l}\text { No objective measures of } \\
\text { efficacy; can worsen fibrosis; } \\
\text { high recurrence rate }\end{array}$} \\
\hline & Smith et al. [24] (2006) & 7 & & \\
\hline & $\begin{array}{l}\text { Ngugi and Kassim } \\
\text { [25] (2007) }\end{array}$ & 49 & & \\
\hline Urethrotomy & $\begin{array}{l}\text { Massey and Abrams } \\
\text { [22] (1988) }\end{array}$ & 163 & $\begin{array}{l}\text { Minimally invasive, } \\
\text { office based }\end{array}$ & $\begin{array}{l}\text { No objective measures of } \\
\text { efficacy }\end{array}$ \\
\hline Meatotomy & $\begin{array}{l}\text { Heising and Seifirth } \\
\text { [27] (1978) }\end{array}$ & 50 & $\begin{array}{l}\text { Little risk of } \\
\text { incontinence }\end{array}$ & Possible spraying with voiding \\
\hline \multirow[t]{2}{*}{ Vaginal inlay flap } & $\begin{array}{l}\text { Schwender et al. } \\
{[20](2006)}\end{array}$ & 8 & \multirow{2}{*}{$\begin{array}{l}\text { Durability, low morbidity; } \\
\text { minimal risk of } \\
\text { incontinence }\end{array}$} & \multirow{2}{*}{$\begin{array}{l}\text { Low risk of recurrent stenosis; } \\
\text { persistence of irritative } \\
\text { symptoms }\end{array}$} \\
\hline & Gormley [29] (2010) & 12 & & \\
\hline $\begin{array}{l}\text { Labia minora } \\
\text { pedicle flap }\end{array}$ & Tanello et al. [30] (2002) & 2 & Low morbidity & $\begin{array}{l}\text { Inadequate experience to define } \\
\text { efficacy }\end{array}$ \\
\hline $\begin{array}{l}\text { Dorsal vestibular } \\
\text { flap }\end{array}$ & Montorsi et al. [31] (2002) & 17 & $\begin{array}{l}\text { Objective improvement } \\
\text { in voiding }\end{array}$ & Risk of bleeding, incontinence \\
\hline $\begin{array}{l}\text { Free labia minora } \\
\text { skin flap }\end{array}$ & Rehder et al. [34] (2010) & 8 & $\begin{array}{l}\text { Improved voiding, } \\
\text { continence }\end{array}$ & Risk of recurrent stricture \\
\hline Ventral buccal graft & Berglund et al. [35] (2006) & 2 & $\begin{array}{l}\text { Useful for extensive } \\
\text { strictures }\end{array}$ & Risk of meatal stenosis \\
\hline Dorsal buccal graft & Migliari et al. [21] (2006) & 3 & $\begin{array}{l}\text { Improvement on } \\
\text { urodynamics }\end{array}$ & $\begin{array}{l}\text { Persistence of irritative } \\
\text { symptoms }\end{array}$ \\
\hline Dorsal lingual graft & Sharma et al. [37] (2009) & 15 & Normal uroflows & Risk of submeatal stenosis \\
\hline
\end{tabular}

with very low morbidity. To our knowledge, however, results of this technique have not been reported in the literature. If the dorsal aspect of the urethra remains extensively scarred, and the resultant lumen insufficient, then this technique would be suboptimal and would risk stricture recurrence.

\section{Excision and Reanastomosis}

Excision and reanastomosis is feasible in women but carries greater morbidity than ventral onlay flap-based approaches. Dorsal mobilization of the urethra can result in bleeding and, potentially, stress urinary incontinence. A circumferential urethral stricture associated with significant spongiofibrosis, however, may warrant such a repair if an onlay does not provide adequate urethral caliber. Care must be taken to avoid excessive mobilization of the urethra distal to the stricture, as there is a potential risk of urethral devascularization. There is a paucity of data in the literature describing this technique in the treatment of female stricture, although Rovner and Wein [28] described its success in the management of complex urethral diverticula.

\section{Flap-based Urethroplasty in Women}

Flap-based urethroplasty techniques have demonstrated efficacy and safety and are the treatment of choice for most female urethral strictures. To obtain durable results, mobilization of a generous flap is paramount, as it will contract with healing. As for all flaps, preservation of a substantial vascular pedicle promotes tissue viability. The most popular flap techniques include vaginal wall and labial skin flaps. One appealing characteristic of local vaginal wall flaps is that they are well-vascularized and freely mobile, allowing mobilization of the flap without undermining tissue. Furthermore, use of the vaginal wall has the lowest morbidity of any flap-based procedure. Schwender et al. [20] treated eight patients with urethral strictures refractory to dilation or urethrotomy using a vaginal inlay flap. An inverted U incision was made in the vaginal epithelium, with the apex at the urethral meatus. A 3-cm flap was developed, with the plane of dissection between the ventral aspect of the urethra and the vaginal mucosa. Again, the urethra was incised ventrally from the meatus to healthy urethral tissue. The flap was inverted, bringing the apex of the vestibular flap to the genu of the incised urethra and reapproximating the remaining tissues. Although urodynamic parameters were not assessed, the average caliber of the urethra increased from $9.25 \mathrm{~F}$ preoperatively to $16.5 \mathrm{~F}$. All patients had subjective improvement of irritative symptoms without immediate or delayed complications or the development of stress incontinence. One patient experienced narrowing at the bladder neck that required operative dilation for resolution. Gormley [29] recently reported durability with very low morbidity in an updated series of 12 women who underwent a simple vaginal inlay flap. 
Tanello et al. [30] described the use of a pedicle flap from the labia minora as treatment for distal stricture in two patients. First, the urethra was exposed through an incision in the anterior vaginal wall, separating the vagina from the urethra via periurethral dissection. An incision was made ventrally from the meatus to healthy, nonfibrotic urethral tissue. A flap raised from the labia minora was rotated through a tunnel created underneath the vaginal wall to the urethra. The flap was sutured to the margins of the defect, with the epithelial surface toward the urethral lumen and the vaginal wall closed. Both patients had excellent outcomes, with normal micturition and resolution of stricture on cystourethrography at 2 years.

In one of the largest series, Montorsi et al. [31] used a dorsal approach to treat 17 patients with symptomatic distal or meatal urethral stricture. This study had the most stringent inclusion criteria, requiring AUA score greater than 20, urodynamic evidence of obstruction, urethral calibration less than $20 \mathrm{~F}$, and radiologic evidence of stricture. An inverted Y-shaped incision was made around the meatus, and the distal $3 \mathrm{~cm}$ of the urethra was dissected away from the perimeatal tissue from 9 o'clock to 3 o'clock. The urethra was incised at 12 o'clock until the proximal urethra could pass a $30-\mathrm{F}$ bougie à boule. A $1-\mathrm{cm}-\mathrm{by}-3-\mathrm{cm}$ vestibular flap with underlying muscular tissue was raised superior to the urethra. The distal tip of the flap was anastomosed to the proximal urethral margin, with the epithelial surface facing the urethral lumen. After 3 months, mean maximum flow rate improved from 13.2 to $36 \mathrm{~mL} / \mathrm{s}$, mean detrusor pressure at maximum flow rate decreased from 45 to $17 \mathrm{~cm} \mathrm{H}_{2} \mathrm{O}$, and average postvoid residuals were reduced from 120 to $20 \mathrm{~mL}$. The AUA symptom score decreased from 25.2 to 8.4. Only 2 of the 17 patients $(12 \%)$ complained of persistent obstructive voiding symptoms despite an improvement in urethral caliber.

\section{Use of Grafts in Female Urethroplasty}

The use of grafts in female urethroplasty has demonstrated feasibility. Unlike in men, in whom buccal mucosa grafts have demonstrated superiority to skin-based flaps, in women there are no data comparing the use of grafts with that of vaginal or labial flaps. In addition, there are no data demonstrating the superiority of a dorsal approach over a ventral approach. Although graft use, particularly buccal and lingual grafts, is typically well-tolerated, the low, but significant, risk of damage to the salivary glands exists [32, 33]. In addition, a dorsal approach to urethroplasty in women may carry a higher risk of bleeding and possible injury to the clitoris or crura. As the available data merely demonstrate feasibility, caution should be taken before embarking on approaches that add morbidity without improving outcome. With those caveats in mind, we believe that for distal strictures that do not impact on the continence mechanism, there is little role for dorsal urethroplasty unless the ventral wall is extensively scarred. For strictures that involve the sphincter and those that extend to the bladder neck, however, a dorsal approach may be preferable for two reasons. First, the chance of ureteral injury is negligible. Second, the chance of sphincter damage is also decreased, especially when the dissection proceeds between the urethra and extraurethral striated muscles.

A procedure using a ventral free labia minora skin graft was performed by Rehder et al. [34] in eight patients with proximal urethral strictures. Without mobilizing the urethra, an incision was made in the anterior vaginal wall and urethra at the 6-o'clock position until the entirety of the stricture was spatulated. A diamond-shaped thin free skin graft (at least one third longer than the defect length) was taken from the labium minora, cleared of all subcutaneous tissue, and perforated to allow wound secretion. The graft was then sutured into the defect, and the anterior vaginal wall closed in two layers over a catheter. At 1- and 2-year follow-up, seven and six patients reported significant improvement in voiding symptoms, respectively; all remained continent. Of the two who were not improved, one developed a meatal stenosis that was treated with urethrotomy, while the other developed a subsequent catheterization-related stricture requiring a second urethroplasty. Again, although it is feasible, we would recommend that this technique be used only when there is insufficient local vaginal wall tissue for a pedicle flap.

As in male urethroplasty, several groups have used buccal and lingual grafts to expand strictured regions. Berglund et al. [35] described management of two patients with urethral stricture with ventral buccal graft urethroplasty. The urethra was exposed through a midline anterior vaginal incision; once isolated, the stricture was incised along the ventral surface. A buccal graft-harvested and processed as in male urethroplasty [36] — was sutured to the edges of the incised urethra, and the repair was covered with periurethral tissue using a Martius flap when inadequate periurethral tissue was available. One patient had a complete resolution of symptoms, while the other developed a meatal stenosis distal to the graft requiring dilation.

Migliari et al. [21] used urethroplasty using a dorsal buccal graft to treat three patients with urethral strictures. A suprameatal inverted $U$ incision was made from the 3o'clock to the 9-o'clock position. The urethra was mobilized inferiorly, developing a plane dorsally between the urethra and the overlying clitoral bodies. Following incision of the stricture, a $5-\mathrm{cm}-$ by-3-cm buccal graft was sutured in place to the defect and quilted to the clitoral bodies to provide structural and vascular support. The surrounding 
tissues were reapproximated over a catheter. In 2 years of follow-up, all three patients obtained a nonobstructive pattern on urodynamics. No significant complications occurred. A similar procedure was attempted with dorsal onlay lingual mucosal grafts in 15 women with a history suggestive of urethral stricture refractory to multiple previous dilations or urethrotomy [37]. The dorsal aspect of the urethra was exposed as above using a suprameatal inverted U incision; urethrotomy at the 12-o'clock position opened the strictured urethral segment. Lingual mucosal graft was harvested from the ventrolateral aspect of the tongue and sutured to the defect. The vaginal incisions were closed over a catheter. On uroflow, all patients had normal flow rate curves postoperatively. One patient $(7 \%)$ developed a submeatal stenosis that was treated with monthly office dilation; none of the patients developed neurosensory complications, incontinence, or graft necrosis.

\section{Urethral Distraction in the Setting of Pelvic Trauma}

Pelvic fracture-associated urethral distraction injuries occur much less frequently in women than men and are more common in girls than in women. In men with urethral distraction defects, anastomotic repair in the acute setting is discouraged. Delayed primary endoscopic realignment in men (within 7-10 days of injury) shortens the defect and in some cases realigns the urethra sufficiently such that adequate mucosal coaptation exists and definitive urethroplasty is avoided. In women, however, realignment is not adequate; allowing the distraction to obliterate will result in the need for a very complex reconstruction with a high risk of incontinence. Whenever possible, anastomotic urethroplasty should be performed vaginally in the primary setting once the patient is hemodynamically stable (preferably within 23 days of injury). An associated vaginal laceration often occurs at the site of urethral distraction and can be used as a guide. The urethra is first realigned under cystoscopic guidance, which may require endoscopy from a suprapubic tube tract if the bladder cannot be found by retrograde urethroscopy. Once the urethra is realigned over a wire, a catheter can be placed in the bladder, and the length of the defect assessed. The bladder usually is surprisingly mobile and can be anastomosed to the proximal urethra from an entirely vaginal approach. Although stress incontinence may result from associated pudendal neuropathy or sphincteric damage, a sling can be placed at a later date.

When a large defect is present and primary urethroplasty is not performed, a much more complex operation is necessary. Minimal data are available examining possible reconstructive methods. In seven young girls with urethral injuries after pelvic fracture, Hosseini et al. [38] performed a retropubic urethroplasty procedure. Following a suprapubic incision, the bladder neck was released, and the fibrous tissue around the strictured proximal urethra was removed under flexible cystoscopic guidance. This proximal stump was anastomosed to the distal end of the urethra. In two patients with extension of fibrosis into the bladder neck, an omental flap was wrapped around the anastomosis to promote continence. All patients demonstrated unobstructed voiding after catheter removal. One patient with concomitant vaginal lacerations later developed an urethrovaginal fistula, which resolved with antibiotics and placement of an indwelling Foley catheter.

$\mathrm{Xu}$ et al. [39] treated eight female patients with complex urethral obliteration and urethrovaginal fistulas secondary to pelvic fractures with tubularized labial pedicle flaps in a delayed fashion. In five patients, a single 3.5cm-by-3-cm flap from the labia minora or majora was mobilized on a vascular pedicle and tubularized over an 18- to $22-\mathrm{F}$ catheter to create a neourethra. In the remaining three patients, bilateral $1.5-\mathrm{cm}-\mathrm{by}-3-\mathrm{cm}$ flaps were taken and sutured together with the epithelial surfaces lining the inside of the tube. Through a low midline incision above the pubic symphysis, a portion of the pubic bone was removed to expose the urethra. Fibrosed tissue and damaged urethra were removed completely, and any associated vaginal injuries were repaired. The remaining normal urethra and neourethra were connected via tension-free anastomosis and wrapped in a rectus muscle pedicle flap to prevent fistula formation, provide blood supply, and preserve continence. With a mean follow-up of 4 years, only one complained of difficulty voiding postoperatively and was treated successfully with dilation. The remainder had normal voiding with an average maximum flow rate of $23.9 \mathrm{~mL} / \mathrm{s}$ (range, $18-42 \mathrm{~mL} / \mathrm{s}$ ).

\section{Conclusions}

No consensus currently exists for the treatment of urethral strictures in women. Unlike in men, female distraction injuries should be addressed with primary urethroplasty after the patient is stabilized hemodynamically. We recommend that dilation or urethrotomy be used judiciously in women with a true urethral stricture. With stricture recurrence after dilation, or in patients with severe stricture disease, proceeding to urethroplasty is recommended. Most methods seem efficacious from the limited data available, allowing surgeons to choose an approach based on stricture characteristics and individual comfort with each approach. Intuitively, ventrally approached techniques using vaginal 
wall or labial flaps seem to be the least morbid in women. Stress incontinence resulting from urethroplasty can be addressed with a sling in a second stage. Although concomitant placement of a pubovaginal sling has been described for coexistent bladder neck incompetence [40•], the safety of combining a sling with urethroplasty has not been proven.

Disclosure Dr. Blaivas has served as a consultant for Pfizer, NovaSys Health Network, and Astellas Pharma US and owns stock/ stock options in Endogun Medical Systems and HDH Pharma. Drs. Ackerman and Anger reported no potential conflicts of interest relevant to this article.

Open Access This article is distributed under the terms of the Creative Commons Attribution Noncommercial License which permits any noncommercial use, distribution, and reproduction in any medium, provided the original author(s) and source are credited.

\section{References}

Papers of particular interest, published recently, have been highlighted as:

- Of importance

1. Carr LK, Webster GD: Bladder outlet obstruction in women. Urol Clin North Am 1996, 23:385-391.

2. Nitti VW, Tu LM, Gitlin J: Diagnosing bladder outlet obstruction in women. J Urol 1999, 161:1535-1540.

3. Groutz A, Blaivas JG, Chaikin DC: Bladder outlet obstruction in women: definition and characteristics. Neurourol Urodyn 2000, 19:213-220.

4. Kuo HC: Videourodynamic characteristics and lower urinary tract symptoms of female bladder outlet obstruction. Urology 2005, 66:1005-1009.

5. Indudhara R, Vaidyanathan S, Radotra BD: Urethral tuberculosis. Urol Int 1992, 48:436-438.

6. Romero Perez P, Schiefenbusch Munne E, Lobato Encinas JJ, Mira Llinares A: [Female urethral stenosis caused by vulvar dystrophy.] Arch Esp Urol 1990, 43:341-346.

7. Pugliese JM, Morey AF, Peterson AC: Lichen sclerosus: review of the literature and current recommendations for management. J Urol 2007, 178:2268-2276.

8. Desai S, Libertino JA, Zinman L: Primary carcinoma of the female urethra. J Urol 1973, 110:693-695.

9. Yamashita T, Masuda H, Yano M, et al.: Female urethral fibroepithelial polyp with stricture. J Urol 2004, 171:357.

10. Ozel B, Ballard C: Urethral and paraurethral leiomyomas in the female patient. Int Urogynecol J Pelvic Floor Dysfunct 2006, 17:93-95.

11. Stephanian E, Gruessner RW, Brayman KL, et al.: Conversion of exocrine secretions from bladder to enteric drainage in recipients of whole pancreaticoduodenal transplants. Ann Surg 1992, 216:663-672.

12. Nielsen KT, Christensen MM, Olesen S: Urethral strictures after transurethral bladder tumor resection. Scand J Urol Nephrol 1989, 23:81-83.
13. Nieuwenhuijs JL, De Jong TP: Two cases of unusual urethral complications after resection of sacrococcygeal teratoma. J Pediatr Surg 2003, 38:E14-E15.

14. Cavadas PC, Landin L: Treatment of urethral stricture in a femaleto-male transsexual with a tubulized flap from the labia minora. J Reconstr Microsurg 2005, 21:153-156.

15. Farrar DJ, Osborne JL, Stephenson TP, et al.: A urodynamic view of bladder outflow obstruction in the female: factors influencing the results of treatment. Br J Urol 1975, 47:815-822.

16. Rees DL, Whitfield $\mathrm{HN}$, Islam $\mathrm{AK}$, et al.: Urodynamic findings in adult females with frequency and dysuria. Br J Urol 1975, 47:853-860.

17. Merimsky E: Retention secondary to urethral stricture in the female. Urology 1985, 26:598.

18. Romero Perez P, Mira Llinares A: [Renal and ureteral complications of urethral stenosis.] Actas Urol Esp 1995, 19:432-440.

19. Santucci RA, Payne CK, Anger JT, Saigal CS: Office dilation of the female urethra: a quality of care problem in the field of urology. J Urol 2008, 180:2068-2075.

20. Schwender CE, Ng L, McGuire E, Gormley EA: Technique and results of urethroplasty for female stricture disease. J Urol 2006 , 175:976-980.

21. Migliari R, Leone P, Berdondini E, et al.: Dorsal buccal mucosa graft urethroplasty for female urethral strictures. J Urol 2006, 176:1473-1476.

22. Massey JA, Abrams PH: Obstructed voiding in the female. Br J Urol 1988, 61:36-39.

23. Takao M, Asano T, Nakamura H: [Urodynamic studies before and after gradual urethral dilatation with metal sounds for female urethral stricture.] Hinyokika Kiyo 1992, 38:15-17.

24. Smith AL, Ferlise VJ, Rovner ES: Female urethral strictures: successful management with long-term clean intermittent catheterization after urethral dilatation. BJU Int 2006, 98:96-99.

25. Ngugi PM, Kassim A: Clean intermitent catheterisation in the management of urethral strictures. East Afr Med J 2007, 84:522-524.

26. - Stein TA, DeLancey JO: Structure of the perineal membrane in females: gross and microscopic anatomy. Obstet Gynecol 2008, 111:686-693. This is an excellent description of the anatomy of the perineum in females, with detailed drawings and anatomic sections that display the important structures surrounding the surgical field during urethroplasty.

27. Heising J, Seiferth J: [Meatus stenosis of girls - clinical demonstration and therapy (author's translation).] Urologe A 1978, 17:292-295.

28. Rovner ES, Wein AJ: Diagnosis and reconstruction of the dorsal or circumferential urethral diverticulum. J Urol 2003, 170:82-86; discussion 86.

29. Gormley EA: Vaginal flap urethroplasty for female urethral stricture disease. Neurourol Urodyn 2010, 29(Suppl 1):S42-S45.

30. Tanello M, Frego E, Simeone C, Cosciani Cunico S: Use of pedicle flap from the labia minora for the repair of female urethral strictures. Urol Int 2002, 69:95-98.

31. Montorsi F, Salonia A, Centemero A, et al.: Vestibular flap urethroplasty for strictures of the female urethra. Impact on symptoms and flow patterns. Urol Int 2002, 69:12-16.

32. Canning DA: Oral complications after buccal mucosal graft harvest for urethroplasty. J Urol 2005, 173:2145.

33. Kumar A, Goyal NK, Das SK, et al.: Oral complications after lingual mucosal graft harvest for urethroplasty. Aust N Z J Surg 2007, 77:970-973.

34. Rehder P, Glodny B, Pichler R, et al.: Dorsal urethroplasty with labia minora skin graft for female urethral strictures. BJU Int 2010 Mar 4 (Epub ahead of print).

35. Berglund RK, Vasavada S, Angermeier K, Rackley R: Buccal mucosa graft urethroplasty for recurrent stricture of female urethra. Urology 2006, 67:1069-1071. 
36. Morey AF, McAninch JW: Technique of harvesting buccal mucosa for urethral reconstruction. J Urol 1996, 155:16961697.

37. Sharma GK, Pandey A, Bansal H, et al.: Dorsal onlay lingual mucosal graft urethroplasty for urethral strictures in women. BJU Int 2010, 105:1309-1312.

38. Hosseini J, Tavakkoli Tabassi K, Razi A: Delayed retropubic urethroplasty of completely transected urethra associated with pelvic fracture in girls. Urol J 2009, 6:272-275.
39. Xu YM, Sa YL, Fu Q, et al.: Transpubic access using pedicle tubularized labial urethroplasty for the treatment of female urethral strictures associated with urethrovaginal fistulas secondary to pelvic fracture. Eur Urol 2009, 56: 193-200.

40. - Blaivas JG, Purohit RS: Post-traumatic female urethral reconstruction. Curr Urol Rep 2008, 9:397-404. This review addresses the potential approaches to the reconstruction of a stenotic urethra following pelvic surgery, pelvic fracture, long-term indwelling Foley catheterization, or pelvic radiation. 